\title{
Volatile Profile Comparison of USDA Sweet Orange-like Hybrids versus 'Hamlin' and 'Ambersweet'
}

\author{
Jinhe Bai ${ }^{1}$, Elizabeth Baldwin, Jack Hearn, Randy Driggers, \\ and Ed Stover \\ USDA, ARS, USHRL, 2001 S. Rock Road, Ft. Pierce, FL 34945 \\ Additional index words. alcohol, aldehyde, Citrus, ester, flavor, terpene hydrocarbon
}

\begin{abstract}
Six 'Ambersweet'-derived hybrids, similar to sweet orange fruit size, color, and taste and potential as new sweet orange cultivars, were selected to determine their fruit categorization by comparison of their volatile profiles with the parent and 'Hamlin', a typical sweet orange. All hybrids are at least $1 / 2$ sweet orange and varying amounts of mandarin, grapefruit, Poncirus trifoliata, and sour orange in each pedigree. In total, 135 volatiles were detected in the eight hybrid lines/commercial cultivars over two harvests, and 20 compounds were detected in all samples, including terpenes (limonene, $\beta$-myrcene, $\alpha$-pinene, $\alpha$-terpinene, $\alpha$-terpineol, and linalool), esters (ethyl butanote, ethyl pentanoate, and ethyl acetate), aldehydes (acetaldehyde, hexanal, and nonanal), and alcohols (ethanol and hexanol). Total abundance of volatiles in January-harvested fruits averaged $30 \%$ higher than for fruits of the same trees harvested in November. 'Ambersweet' contained the highest total amount of volatiles (mainly as a result of very high levels of monoterpenes), and of them, nootkatone and six other compounds were not detected in any of the hybrids, and some of them were also not detected in 'Hamlin'. On the other hand, 12 compounds, including pentanal, ethyl 2-butenoate, and ethyl nonanoate, were not detected in 'Ambersweet' but were found in 'Hamlin' and some of the hybrids. Cluster analysis separated the cultivar/hybrid and harvest time combinations into three clusters. FF-1-76-50, FF-1-76-52 and January FF-1-75-55, all with the same parents ('Ambersweet' $\times$ FF-1-30-52), were close to FF-1-65-55, but they were separated from 'Hamlin' and further separated from 'Ambersweet'. The cluster containing 'Hamlin' has three subclusters: January 'Hamlin' and November FF-1-74-14, a hybrid with one-eighth $P$. trifoliata, which includes a slight off-flavor frequently found in $P$. trifoliata hybrids, independent of each other, and both were separated from a group of November 'Hamlin', FF-1-64-97, and FF-1-75-55. The cluster containing 'Ambersweet' included January FF-1-64-97. A principle component analysis (PCA) separated 'Ambersweet' from all hybrids and 'Hamlin' along the PC1 axis and separated November harvests from January harvests along PC2. This volatile analysis supports the classification of the hybrids as sweet orange.
\end{abstract}

'Hamlin' is the dominant early-maturing sweet orange [Citrus $\times$ sinensis (L.) Osbeck] variety in Florida, which is used mainly for juice processing. However, like other sweet oranges, 'Hamlin' has low resistance to Huanglongbing (HLB, also called citrus greening), a very destructive citrus disease that has affected Florida citrus production since 2005 (Folimonova et al., 2009; Stover and McCollum, 2011). On the other hand, Poncirus trifoliata (L.) Raf. and C. latipes (Swingle) showed great resistance to HLB

Received for publication 1 July 2014. Accepted for publication 5 Aug. 2014.

Mention of a trademark or proprietary product is for identification only and does not imply a guarantee or warranty of the product by the U.S. Department of Agriculture. The U.S. Department of Agriculture prohibits discrimination in all its programs and activities on the basis of race, color, national origin, gender, religion, age, disability, political beliefs, sexual orientation, and marital or family status.

${ }^{1}$ To whom reprint requests should be addressed; e-mail jinhe.bai@ars.usda.gov. back through three generations is $1 / 2$ sweet orange, $3 / 8$ mandarin, and $1 / 8$ grapefruit $(C$. xparadisi MacFadyen) (Hearn, 1989). Because grapefruit includes sweet orange in its pedigree, 'Ambersweet' actually contains more than $1 / 2$ sweet orange (Fig. 1) (Hearn, 1989; Moshonas et al., 1991). In the last 4 years, six sweet orange-like hybrids with 'Ambersweet' as one parent have been selected for evaluation as potential cultivars (Fig. 1). All these hybrids are derived at least $1 / 2$ from sweet orange and include varying amounts of additional mandarin (not through sweet orange), grapefruit, $P$. trifoliata, and sour orange $(C$. Xaurantium L.) in their pedigrees (Fig. 1). Although it appears that the genes from mandarin, which contribute to currently available sweet orange varieties, convey little resistance to HLB, other genes in mandarin may convey commercially useful tolerance to HLB. Observations showed that all the new hybrids are early-maturing and are very sweet orange-like in fruit size, color, and taste, and thus have potential as improved sweet oranges. The objective of this research was to compare the volatile profiles of the six hybrids with the common parent, 'Ambersweet', and the representative early-maturing sweet orange, 'Hamlin', to determine whether the profiles would support classification of the hybrids as sweet orange.

\section{Materials and Methods}

Fruit materials and juice preparation. Fruits were harvested from trees of commercial cultivars Hamlin and Ambersweet and six orange hybrids all grown at the A.H. Whitmore Citrus Research Foundation Farm in Leesburg, FL. Hybrids FF-1-74-14 and FF-1-76-50 were only harvested on 15 Nov. 2011. However, other cultivars/hybrids were harvested twice, on 15 Nov. 2011 and 8 Jan. 2012. The pedigree of the hybrids is shown in Figure 1. Briefly, FF-1-75-55, FF-1-76-50, and FF-1-76-52 are from a cross of 'Ambersweet' and FF-1-30-52. Their genetic background through three generations contains $1 / 2$ sweet orange $(C$. Xsinensis $), 7 / 16$ mandarin (C. reticulata) not through sweet orange, and 1/16 grapefruit (C. ×paradisi). FF-1-64-97 and FF-1-65-55 are from a cross of 'Ambersweet' and FF-5-7-5 and their pedigree includes $1 / 2$ sweet orange and $1 / 4$ sour orange $(C$. $\times$ aurantium L.). The last hybrid, FF-1-74-14, is from a cross of 'Ambersweet' and 'US-119', and the genetic background contains $1 / 2$ sweet orange, and $1 / 8 P$. trifoliata. Each sample included five defect-free fruits, and each cultivar/line contained four replicates at each harvest. Fruits were stored overnight at room temperature $\left(25^{\circ} \mathrm{C}\right)$ before juicing

Fruits were hand-washed using a commercial detergent (Fruit Cleaner 395; JBT Food Tech., Lakeland, FL) and dried using paper towels. Fruits of uniform size and color were gently juiced by hand, to avoid peel oil entering the juice, using a kitchen juicer with an automatic self-reversing reamer (Oster Model 3183; Household Appliance Sales 


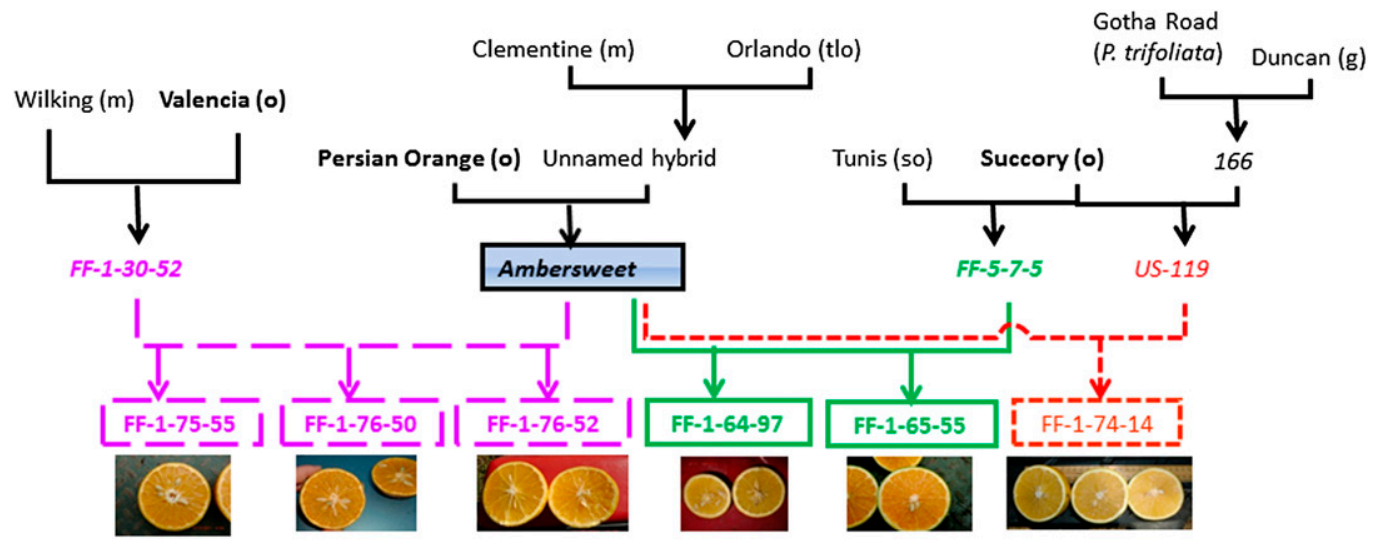

(g): grapefruit (C. $\times$ paradisi); $(\mathrm{m})$ : mandarin (C. reticulata); (o): sweet orange (C. $\times$ sinensis); (so): sour orange (C. $\times$ aurantium); (tlo): tangelo (mandarin -grapefruit hybrid).

Grapefruit, sweet orange and sour orange are also hybrids as follows: grapefruit [pummelo (C. maxima) -sweet orange hybrid], sweet orange (mandarin -pummelo hybrid) and sour orange (mandarin -pummelo hybrid).

Fig. 1. Pedigree of 'Ambersweet' and the hybrids (boxed) used in this research.

and Service, Niles, IL). A 6-mL volume of each juice sample was pipetted into a $20-\mathrm{mL}$ vial and was crimp-capped with a Teflon/ silicone septum. Sample vials were stored at $-80{ }^{\circ} \mathrm{C}$ until analyzed.

For headspace sampling and gas chromatography-mass spectrometry (GC-MS) analysis, frozen sample vials were thawed under tap water and loaded into the autosampler (Model MPS2; Gerstel Inc., Linthicum, MD) equipped with a cooled tray holder [a cooling plate (Laird Tech, Sweden) controlled by a Peltier thermostat (CTC Analytics AG, Switzerland)]. Samples were held 0 to $16 \mathrm{~h}$ at $4{ }^{\circ} \mathrm{C}$ in the cooled tray until analyzed. For analysis, juice samples were incubated for 30 min at $40{ }^{\circ} \mathrm{C}$. A $2-\mathrm{cm}$ solid phase microextraction (SPME) fiber $(50 / 30 \mu \mathrm{m} \mathrm{DVB} /$ Carboxen/PDMS; Supelco, Bellefonte, PA) was then exposed to the headspace for 30 $\min$ at $40{ }^{\circ} \mathrm{C}$. After exposure, the SPME fiber was inserted into the injector of a GC-MS (Model 6890; Agilent Technologies, Santa Clara, CA) to desorb the extract for $15 \mathrm{~min}$ at $250^{\circ} \mathrm{C}$. The GC-MS equipment and settings were: DB-5 (60 m length, $0.25 \mathrm{~mm}$ i.d., $1.00 \mu \mathrm{m}$ film thickness; J\&W Scientific, Folsom, CA) columns coupled with a $5973 \mathrm{~N}$ MS detector (Agilent Technologies). The column oven was programmed to increase at $4{ }^{\circ} \mathrm{C} \cdot \mathrm{min}^{-1}$ from the initial $40{ }^{\circ} \mathrm{C}$ to $230{ }^{\circ} \mathrm{C}$, then ramped at $100^{\circ} \mathrm{C} \cdot \mathrm{min}^{-1}$ to $260^{\circ} \mathrm{C}$ and held for $11.70 \mathrm{~min}$ for a total run time of $60 \mathrm{~min}$. Helium was used as carrier gas at flow rate of $1.5 \mathrm{~mL} \cdot \mathrm{min}^{-1}$. Inlet, ionizing source, and transfer line were kept at 250,230 , and $280{ }^{\circ} \mathrm{C}$, respectively. Mass units were monitored from 30 to $250 \mathrm{~m} / \mathrm{z}$ and ionized at $70 \mathrm{eV}$. Data were collected using the ChemStation G1701 AA data system (Hewlett-Packard, Palo Alto, CA). A mixture of C-5 to C-18 n-alkanes was run at the beginning of each day to calculate retention indices (RIs) (Bai et al., 2011).

Volatile compounds were identified by comparison of their mass spectra with authentic volatile compound standards and/or library entries (NIST/EPA/NIH Mass Spectral Library,
Version 2.0d; National Institute of Standards and Technology, Gaithersburg, MA), as well as by comparing RIs with published RIs (Adams and Brown, 2007; Kondjoyan and Berdagué, 1996). Quantification for 21 selected major aroma active volatile components was conducted by using a peak size vs. concentration curve built by serially diluted five-point standard solutions (Bai et al., 2002; Baldwin et al., 2010). Briefly, a standard compound was dissolved in pure methanol and the mixture was then introduced into a sugar equivalent deodorized orange juice (diluted "pumpout" concentrate) (Plotto et al., 2004). The range of concentrations in the standard curve for each compound covers the concentrations found in the samples.

SAS Version 9.3 (SAS Institute, Cary, NC) was used for statistical analysis of volatile data. Principle component analysis (PROC PRINCOMP and a PC1 $\times$ PC2 plot) and cluster analysis (PROC CLUSTER with complete method and PROC GLM with cluster class) were used to test the distances between cultivars/hybrids. The total ion currents of all 135 peaks (compounds) were used as variables for both analyses.

Individual volatiles were assigned to one of 15 compound classes. The sums in total ion current for these compound classes were analyzed using analysis of variance (PROC ANOVA) from four replicates of each genotype $\times$ harvest date, and the treatment means were separated by Tukey's test at the 0.05 significance level. The same procedure was used for ANOVA of 21 major aroma active volatile components in absolute concentration.

\section{Results and Discussion}

In total, 135 volatiles were detected from the hybrid lines and commercial cultivars over two harvests, and the components were classified to 15 chemical classes (Table 1). Table 2 lists the 21 compounds, which sometimes have significant odor activity at levels found in orange juice (Moshonas et al., 1991;
Perez-Cacho and Rouseff, 2008; PérezLópez and Carbonell-Barrachina, 2006; Shaw, 1991). Ethanol is the most abundant compound with a concentration of 138 to $427 \mathrm{mg} \cdot \mathrm{L}^{-1}$ in different samples (Table 2), which is in the normal range for orange juice (Moshonas and Shaw, 1994; Shaw, 1991). However, in this experiment, with the combination of headspace SPME sampling and GC-MS determination, ethanol contributed very little to the total ion current. The most abundant chemical class was monoterpene hydrocarbons with 20 components representing $62 \%$ to $94 \%$ of the total volatiles in total ion current (Table 1). The major monoterpene hydrocarbons were limonene, $\beta$-myrcene, and $\alpha$-pinene (Table 2). 'Ambersweet' contained extremely high levels of limonene, almost twice that of 'Hamlin' (Table 2). The limonene contents in FF-1-74-14 and FF-1-64-97 were similar to or higher than that of 'Hamlin', whereas all other hybrids had somewhat lower limonene content (Table 2). Limonene has been suggested to be one of the most important contributors to orange flavor (Shaw, 1991); however, others indicate that it is necessary for orange aroma, but not a key flavor impact compound (Plotto et al., 2004), except that high concentrations are associated with development of off-odors as a result of oxidation derivatives in processed juice (Perez-Cacho and Rouseff, 2008). The next most abundant monoterpene was $\beta$-myrcene (Table 2). Although $\beta$-myrcene is an important intermediate used in the perfume industry and possesses a pleasant odor (Behr and Johnen, 2009), it was reported to negatively influence citrus and orange juice flavor (Ahmed et al., 1978; Miyazaki et al., 2012). Table 2 shows that only 'Ambersweet' and FF-1-74-14 (the hybrid with Poncirus in its pedigree) had markedly higher $\beta$-myrcene content compared with the other genotypes. Among the hybrids, content of $\alpha$-pinene followed similar trends as did limonene (Table 2) and total monoterpenes (Table 1 ), and $\alpha$-pinene is a positive contributor to orange juice aroma 


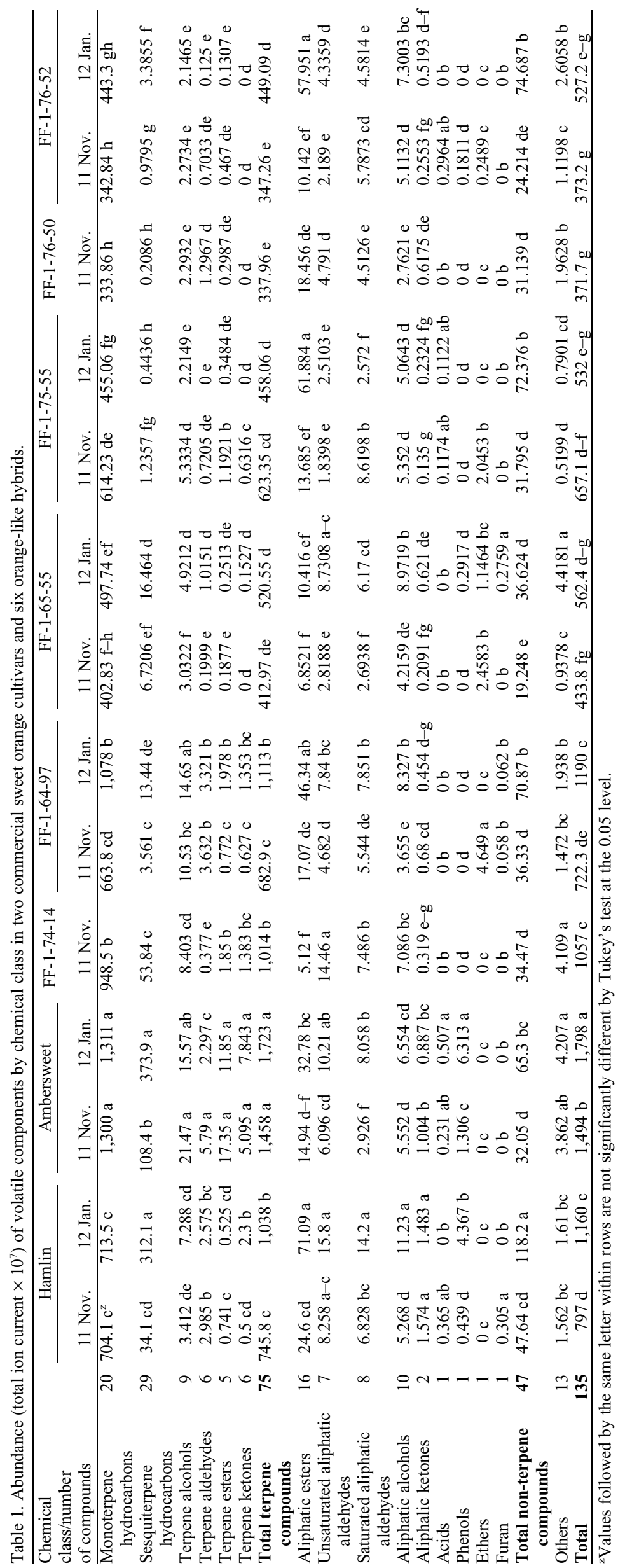

(Shaw, 1991). The concentration of total monoterpenes (limonene, $\beta$-myrcene, $\alpha$-pinene, and other 17 compounds) in 'Ambersweet', FF-1-74-14, and FF-1-64-97 were higher in comparison with other genotypes (Tables 1 and 2).

Sesquiterpene hydrocarbons were the next largest group and the major volatile in the group was valencene (Tables 1 and 2), which possesses a weak, citrus-like aroma (Plotto et al., 2004; Shaw, 1991). 'Hamlin' and 'Ambersweet' had higher valencene levels than the hybrids, although the compound was detected in all the hybrids except in FF-1-76-50 (Table 2); however, it is noteworthy that valencene levels varied almost 10 -fold between harvest dates in 'Hamlin' sweet orange, although the juice met commercial standards for both harvests (Elston et al., 2005). Other important terpene compounds included two terpene alcohols, linalool, and $\alpha$-terpineol and two terpene aldehydes, citral and sinensal (Tables 1 and 2). Both linalool and $\alpha$-terpineol were detected in all samples (Table 2). Linalool is sometimes reported to make a positive contribution to typical orange flavor, although it is not considered a critical compound (Ahmed et al., 1978). A high level of $\alpha$-terpineol is generally considered to be a negative flavor contributor to orange juice and is associated with old and heat-abused products (Tatum et al., 1975). It is formed from linalool and limonene and has a taste threshold of $26 \mathrm{mg} \cdot \mathrm{L}^{-1}$ in orange juice (Plotto et al., 2004), but in this study, even the samples with the highest concentration of $\alpha$-terpineol (November-harvested 'Ambersweet', $0.24 \mathrm{mg} \cdot \mathrm{L}^{-1}$ ) were much lower than this level. Nevertheless, $\alpha$-terpineol is often included in synthetic citrus flavorings (Shaw, 1991). Sinensal is a peel oil component and positively contributes to orange flavor (Plotto et al., 2004; Shaw, 1991) and was detected in all samples except the January samples of FF-1-75-55 (Table 2). Citral, which is reported to positively contribute to orange flavor (Keith and Powers, 1968; Plotto et al., 2004), was found only in 'Hamlin', FF-1-64-97, and FF-1-65-55 (Table 2). Other abundant terpenes include $\gamma$-terpinene, sabinene, 2,4-hexadienal, perilla aldehyde, neryl acetate, citronellyl acetate, $\alpha$-ionone, and nootkatone, which did not have a clear pattern in any specific cultivar/hybrid (data not shown).

For aliphatic compounds, the largest group was esters with 16 components representing $0.5 \%$ to $11.6 \%$ of the total volatiles (Table 1). The important esters giving the fruity top notes in orange juice include ethyl acetate, methyl butanoate, ethyl butanoate, ethyl 2-methylbutanoate, and ethyl 3-hydroxyhexanoate (Perez-Cacho and Rouseff, 2008; Plotto et al., 2008; Shaw, 1991). Ethyl acetate and ethyl butanoate were found in all cultivars and hybrids, and ethyl 3-hydroxyhexanoate was detected in all January-harvested fruits but not in some November-harvested fruits (Table 2). Ethyl 2-methylbutanoate was not detected in 'Ambersweet' and FF-1-65-55, and methyl butanoate was not detected in FF-1-65-55 


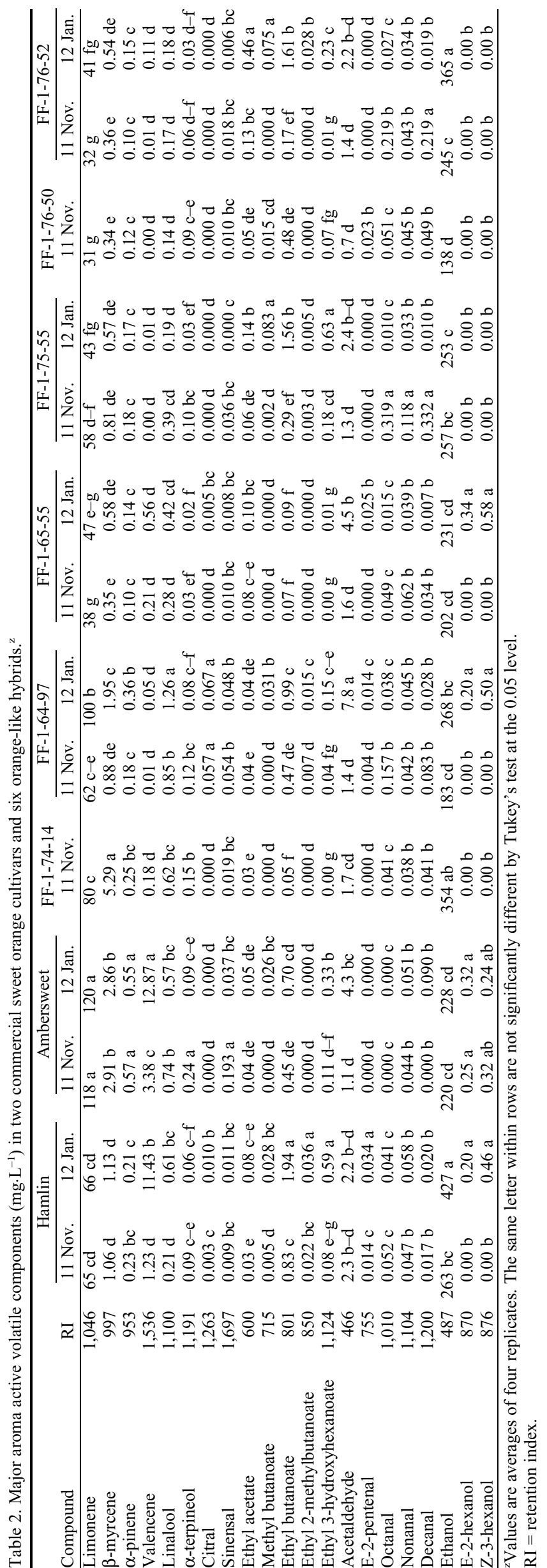

(Table 2). The last two compounds were also not detected in a few other Novemberharvested varieties or hybrids (Table 2). In general, fruits harvested in January had significantly higher aliphatic esters than did fruits harvested in November (Tables 1 and 2).

The aliphatic aldehydes in orange juice, which often contribute citrus-like fruity and green notes, include acetaldehyde, $E$-2-pentenal, octanal, nonanal, and decanal (Perez-Cacho and Rouseff, 2008; Shaw, 1991). Acetaldehyde, nonanal, and decanal were found in all cultivars/lines and octanal was found in all samples but 'Ambersweet' (Table 2). On the other hand, E-2-pentenal was only detected in 'Hamlin', FF-1-64-97, FF-1-76-50, and January-harvested FF-1-65-55 (Table 2).

The important aliphatic alcohols include ethanol, E-2-hexenol, and Z-3-hexenol (Perez-Cacho and Rouseff, 2008; Shaw, 1991). Ethanol was found in all samples but likely has minimal practical significance because of the high sensory threshold (PérezLópez and Carbonell-Barrachina, 2006) and a narrow range of differences across all samples (Table 2). E-2-hexenol and Z-3-hexenol were not at detectable levels in most of the hybrids (Table 2).

The total abundance of volatiles in January-harvested fruits was generally higher than that in the November-harvested fruits from the same genotypes and ranged from a $20 \%$ ('Ambersweet') to a $65 \%$ (FF-1-64-97) increase. Total volatiles decreased in Januaryharvested vs. November-harvested fruits, only in FF-1-75-55 (19\% reduction) (Table 1). 'Ambersweet' contained the highest total amount of volatiles, and of them, nootkatone and six other compounds were not detected in any of the hybrids, and some of them were also not detected in 'Hamlin' (data not shown). On the other hand, 12 compounds, including E-2-pentanal, ethyl 2-butenoate, and ethyl nonanoate, were not detected in 'Ambersweet' but were found in 'Hamlin' and some of the hybrids (data not shown). Twenty compounds were detected in all samples, including limonene, $\beta$-myrcene, $\alpha$-pinene, $\alpha$-terpinene, terpinen- 4 -ol, linalool, ethyl butanote, ethyl pentanoate, ethyl acetate, acetaldehyde, hexanal, nonanal, ethanol, and hexanol (data partially shown in Table 2 and others not shown).

Several methods were used to comprehensively compare genotype $\times$ harvest time data. Cluster analysis separated the 14 cultivar/hybrid and harvest time combinations to three clusters. In the first cluster at the bottom of the figure, November-harvested 'Ambersweet' was in a subcluster with January FF-1-64-97 and they were separated from January 'Ambersweet' with a small but significant distance (Fig. 2). The cluster with these three samples displayed the greatest distance (2.74; Fig. 2) from all other cultivar/hybrids $\times$ harvest time combinations and which were significantly different. In the second cluster, November FF-1-76-50, November and January FF-1-76-52, and January FF-1-75-55, all with the same parents ('Ambersweet' $\times$ FF-1-30-52), were in the same cluster together 
with FF-1-65-55 (Fig. 2). The third cluster included January 'Hamlin' and November FF-1-74-14 (a hybrid with $1 / 8$ P. trifoliata, which includes a slight off-flavor frequently found in $P$. trifoliata hybrids), independent of each other and both separated from a group of November 'Hamlin', FF-1-64-97, and FF-1-75-55 (Fig. 2).
A PCA (Fig. 3) was used to divide the volatile differences into orthogonal groups, resulting in two significant principle components. PC1 explained $38 \%$ and PC2 $14.6 \%$ for a total of $52.6 \%$ of the variation in aroma volatile profiles between the samples, in which each replicate of each genotype at each harvest date was separately represented.
'Ambersweet' was separated from all hybrids and 'Hamlin' along the PC1 axis and the November harvests of 'Ambersweet' were widely separated from the January harvests along PC2. January-harvested 'Hamlin', January-harvested FF-1-64-97, and FF-1-74-14 (the Poncirus hybrid and only harvested in November) each formed distinct clusters,

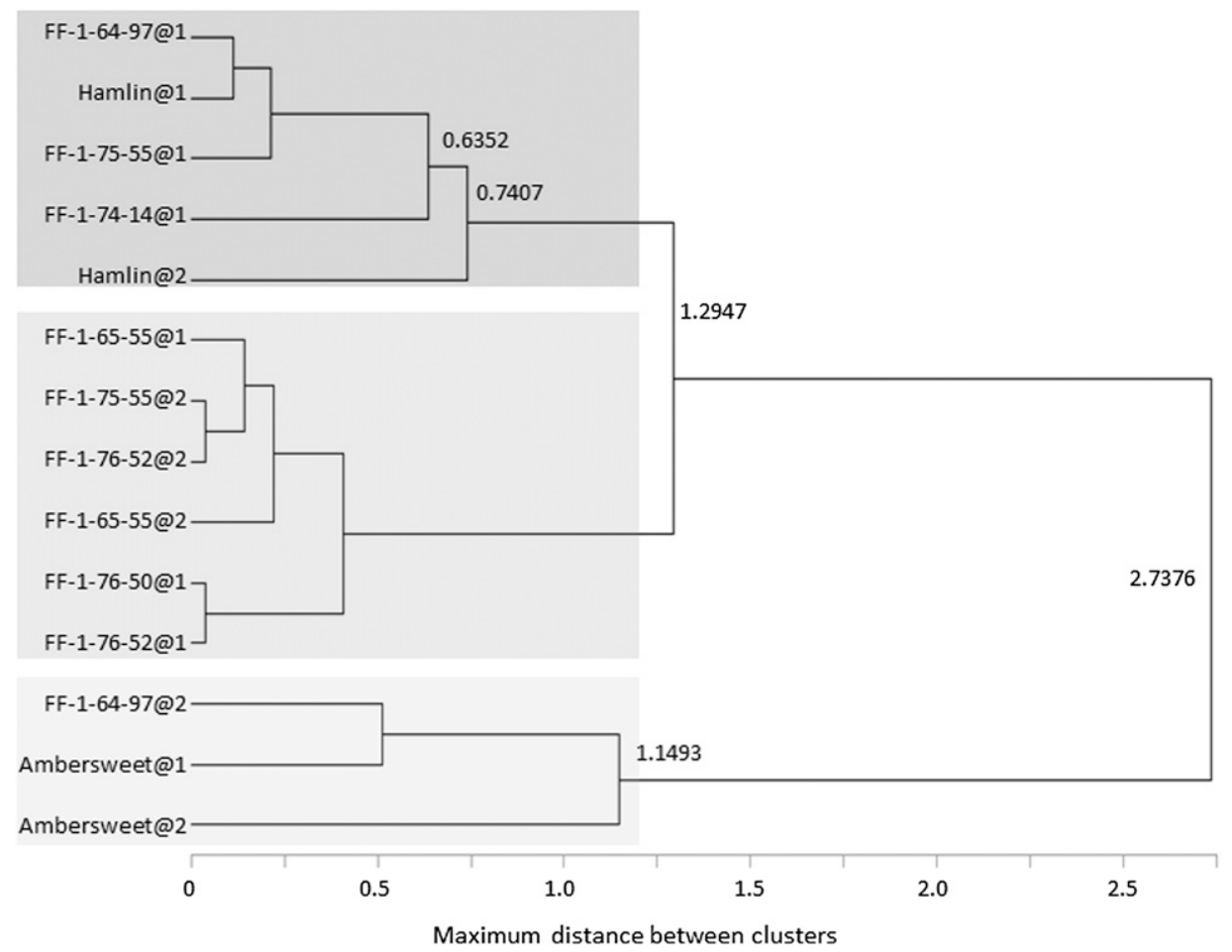

Fig. 2. Cluster analysis of hybrids and commercial sweet orange cultivars based on 135 volatile compounds. Fruits were harvested in Nov. 2011 (@1) and January 2012 (@2).

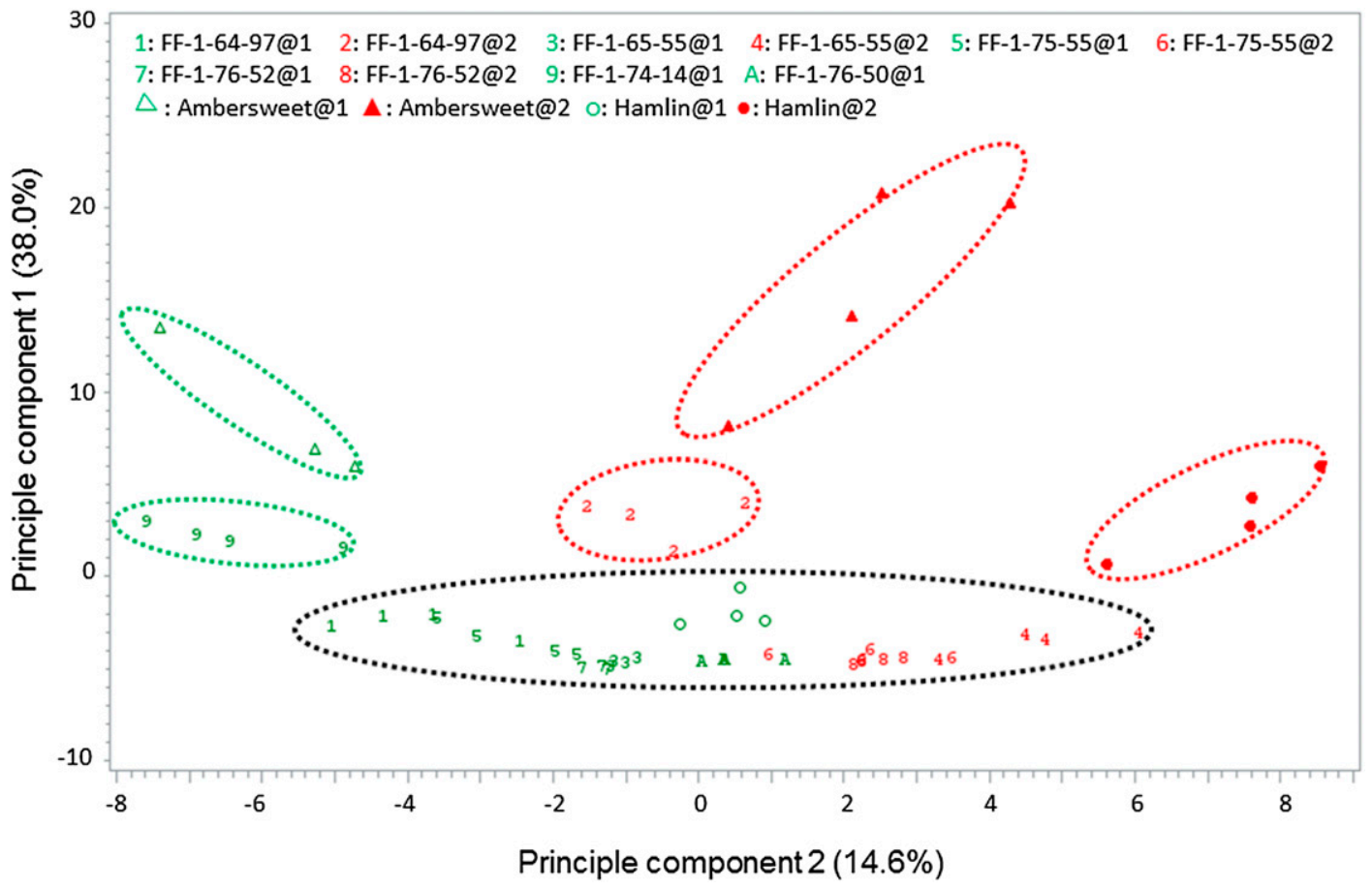

Fig. 3. Principle component analysis of volatile compounds measured in hybrids and commercial sweet orange cultivars. Fruits were harvested in Nov. 2011 (@1) and January 2012 (@2). 
which were not separated by PC1 but distinctly different by PC2. FF-1-64-97, FF-1-65-55, FF-1-75-55, FF-1-76-50, and FF-1-76-52 formed a tight cluster with Novemberharvested 'Hamlin' in PC1 but were loosely clustered in PC2 with January-harvested hybrids being intermediate between November and January-harvested 'Hamlin'. Interestingly, the hybrids FF-1-64-97, FF-1-65-55, FF-1-75-55, and FF-1-76-52 showed much less difference in aroma volatiles between harvest dates than did 'Hamlin' or 'Ambersweet'. Although the $P$. trifoliata hybrid FF-1-74-14 formed its own cluster within the two dimensions, it mapped with Januaryharvested 'Hamlin' in PC1.

Sweet orange has been shown to be a hybrid of the species $C$. reticulata (mandarin) and C. maxima (pummelo) rather than a true species (Barrett and Rhodes, 1976; Nicolosi et al., 2000). The fact that all traditional sweet oranges are almost identical genetically, varying only through mutations, makes sweet orange production a near monoculture that may be especially vulnerable to emerging diseases. 'Ambersweet' is the first cultivar created through hybridization, which has different parentage, but is sufficiently similar in phenotype to be classified as a sweet orange (Hearn, 1989). The hybrid lines included in this study represent recombinations between 'Ambersweet' and additional parents that also derive from sweet orange and were specifically bred and selected to achieve similarity to sweet orange. Like the sweet orange, the pedigrees of all of the plant material included in this study are also derived exclusively from the true species of mandarin and pummelo, except FF-1-74-14, which also includes Poncirus in its pedigree. These facts make it less surprising that the volatile components of these hybrid lines are largely similar to those of sweet orange. It is promising that their volatile profiles are more similar to 'Hamlin' than is their 'Ambersweet' parent, which makes it likely they will be acceptable for sweet orange juice production if they are also shown to have valuable traits such as HLB tolerance as well as similar sugar/acids ratios and without bitter flavonoids or limonoids (Deterre et al., 2013).

Although the aroma profiles are quite similar between 'Hamlin' and most of the investigated hybrids, there are statistically significant differences between levels of some compounds, which are reported to be important contributors to sweet orange aroma. Unlike some other fruits in which aroma is characterized by one or a few compounds, sweet orange aroma results from interactions between numerous compounds with levels of individual constituents varying by harvest time, cultivar, handling, and processing parameters (Perez-Cacho and Rouseff, 2008). Despite this variability, a great majority of commercial juices achieve a product of high quality that is distinctly sweet orange juice. It appears likely that the interaction of many factors in defining sweet orange aroma will more easily permit acceptance of new sweet orange-like hybrids.

Although analysis of numerous aroma volatiles provides useful overall profile comparisons between genotypes, these data also underscore the importance of coupling these analyses with organoleptic evaluation. In informal tasting, the $P$. trifoliata hybrid FF-1-74-14 displayed a distinct off-taste in which one or a few compounds with low perception thresholds likely dominate. It is the combination of volatiles in certain proportions, along with non-volatile compounds (sugars, acids, flavonoids, limonoids, and others), that gives a fruit its specific flavor. Cluster analysis showed that FF-1-74-14 was singled out from the other hybrids simply as a result of its different volatile profile.

In conclusion, six early-season hybrids that are sweet orange-like in fruit size, color, and taste were analyzed for volatile profiles using headspace SPME-GC-MS. Cluster and PCA analysis based on 135 volatile compounds support the classification of these hybrids as sweet orange.

\section{Literature Citied}

Adams, J.B. and H.M. Brown. 2007. Discoloration in raw and processed fruits and vegetables. Crit. Rev. Food Sci. Nutr. 47:319-333.

Ahmed, E.M., R.A. Dennison, and P.E. Shaw. 1978. Effect of selected oil and essence volatile components on flavor quality of pumpout orange juice. J. Agr. Food Chem. 26:368-372.

Bai, J., E. Baldwin, and A. Plotto. 2011. Stability of headspace volatiles in a 'Fallglo' tangerine juice matrix system at room temperature. Proc. Fla. State Hort. Soc. 124:207-212.

Bai, J., R.D. Hagenmaier, and E.A. Baldwin. 2002. Volatile response of four apple varieties with different coatings during marketing at room temperature. J. Agr. Food Chem. 50:7660-7668.

Baldwin, E., A. Plotto, J. Manthey, G. McCollum, J. Bai, M. Irey, R. Cameron, and G. Luzio. 2010. Effect of Liberibacter infection (Huanglongbing disease) of citrus on orange fruit physiology and fruit/fruit juice quality: Chemical and physical analyses. J. Agr. Food Chem. 58:1247-1262.

Barrett, H. and A. Rhodes. 1976. A numerical taxonomic study of affinity relationships in cultivated Citrus and its close relatives. Syst. Bot. 1:105-136.

Behr, A. and L. Johnen. 2009. Myrcene as a natural base chemical in sustainable chemistry: A critical review. ChemSusChem 2:1072-1095.

Deterre, S., T. McCollum, C. Leclair, J. Bai, J. Manthey, J. Salvatore, S. Raithore, E. Baldwin, and A. Plotto. 2013. Secondary metabolite composition in Citrus $\times$ Poncirus trifoliata hybrids. Proc. Fla. State Hort. Soc. 126:206-215.
Elston, A., J. Lin, and R. Rouseff. 2005. Determination of the role of valencene in orange oil as a direct contributor to aroma quality. Flavour Frag. J. 20:381-386.

Folimonova, S.Y., C.J. Robertson, S.M. Garnsey, S. Gowda, and W.O. Dawson. 2009. Examination of the responses of different genotypes of citrus to huanglongbing (Citrus Greening) under different conditions. Phytopathology 99:1346-1354.

Hearn, C.J. 1989. Yield and fruit quality of 'Ambersweet' orange hybrid on different rootstocks. Proc. Fla. State Hort. Soc. 102:75-78.

Keith, E.S. and J.J. Powers. 1968. Determination of flavor threshold levels and sub-threshold, additive, and concentration effects. J. Food Sci. $33: 213-218$.

Kondjoyan, N. and J.-L. Berdagué. 1996. A compilation of relative retention indices for the analysis of aromatic compounds. Laboratoire Flaveur, INRA de THEIX, Saint Genes Champanelle, France

Miyazaki, T., A. Plotto, E.A. Baldwin, J.I. ReyesDe-Corcuera, and F.G. Gmitter, Jr. 2012. Aroma characterization of tangerine hybrids by gas-chromatography-Olfactometry and sensory evaluation. J. Sci. Food Agr. 92:727735 .

Moshonas, M.G. and P.E. Shaw. 1994. Quantitative determination of 46 volatile constituents in fresh, unpasteurized orange juices using dynamic headspace gas chromatography. J. Agr. Food Chem. 42:1525-1528.

Moshonas, M.G., P.E. Shaw, and R.D. Carter. 1991. Ambersweet orange hybrid: Compositional evidence for variety classification. J. Agr. Food Chem. 39:1416-1421.

Nicolosi, E., Z.N. Deng, A. Gentile, S. La Malfa, G Continella, and E. Tribulato. 2000. Citrus phylogeny and genetic origin of important species as investigated by molecular markers. Theor. Appl. Genet. 100:1155-1166.

Perez-Cacho, P.R. and R. Rouseff. 2008. Processing and storage effects on orange juice aroma: A review. J. Agr. Food Chem. 56:9785-9796.

Pérez-López, A.J. and Á.A. Carbonell-Barrachina. 2006. Volatile odour components and sensory quality of fresh and processed mandarin juices. J. Sci. Food Agr. 86:2404-2411.

Plotto, A., C.A. Margaría, K.L. Goodner, and E.A. Baldwin. 2008. Odour and flavour thresholds for key aroma components in an orange juice matrix: Esters and miscellaneous compounds. Flavour Frag. J 23:398-406.

Plotto, A., C.A. Margaría, K.L. Goodner, R. Goodrich, and E.A. Baldwin. 2004. Odour and flavour thresholds for key aroma components in an orange juice matrix: Terpenes and aldehydes. Flavour Frag. J. 19:491-498.

Shaw, P.E. 1991. Fruit II, p. 305-327. In: Maarse, H. (ed.). Volatile compounds in foods and beverages. Marcel Dekker, Inc., New York, NY.

Stover, E. and G. McCollum. 2011. Incidence and severity of huanglongbing and candidatus liberibacter asiaticus titer among fieldinfected citrus cultivars. HortScience 46 : 1344-1348.

Tatum, J.H., S. Nagy, and R.E. Berry. 1975. Degradation products formed in canned single-strength orange juice during storage. J. Food Sci. 40:707-709. 